\title{
Integrando técnicas e procedimentos de gestão de operações: uma aplicação em um banco comercial brasileiro de grande porte
}

\author{
Ualison Rebula de Oliveira, ${ }^{\mathrm{a}, *}$, Fernando Augusto Silva Marins ${ }^{\mathrm{b}}$, \\ Dagoberto Alves de Almeidac \\ a,* ualison.oliveira@gmail.com, FEG-UNESP, Brasil \\ bfmarins@feg.unesp.br, FEG-UNESP, Brasil \\ 'dagoberto@unifei.edu.br, UNIFEl, Brasil
}

\begin{abstract}
Resumo
Na conjuntura atual, eliminação de custos, satisfação dos clientes e aumento da produtividade é algo, no mínimo, desejável para as organizações. Exatamente neste viés, a presente pesquisa aborda a utilização de técnicas e filosofias amplamente abordadas e difundidas em gestão de operações; porém, em vez de usá-las isoladamente, propõe-se sua utilização conjunta. Neste contexto, integram-se o Mapeamento de Processos, a Gestão da Capacidade, a Teoria das Restrições (TOC) e o Empowerment. Por meio de entrevistas junto aos funcionários, da coleta de dados e da observação direta do processo produtivo, foi possível mapear os processos, definir as capacidades, identificar os gargalos, levantar o nível de maturidade dos funcionários e propor soluções por meio da aplicação do Empowerment. Como resultado, contatou-se a possibilidade de melhoria no sistema de concessão de créditos da empresa pesquisada (Banco), possibilitando um aumento da produtividade em 27,78\% e uma redução de custos da ordem de 4,5 milhões de reais. Palavras-chave
\end{abstract}

Gestão da Capacidade. Mapeamento de Processos. Empowerment. Teoria das Restrições.

\section{Introdução}

As empresas têm enfrentado uma grande pressão competitiva e têm reagido a isto implementando, entre outras propostas, inovações tecnológicas, sistemas de gestão da qualidade, personalização dos produtos e dos serviços oferecidos, além de ênfase à Produção Enxuta.

Neste ambiente de alta competição e com a necessidade de se reconquistarem mercados, as empresas precisam ser ágeis e flexíveis; para tanto, precisam conceder mais autonomia a seus funcionários, propiciando uma gestão participativa para a minimização de problemas e maximização de resultados (OLIVEIRA; DELAMARO; MARINS, 2006). A esta concessão de autonomia, dá-se o nome de Empowerment (HONOLD, 1997). Trata-se, no entanto, de tema complexo e sujeito a controvérsias, que envolve aspectos inerentes ao conteúdo e ao contexto do trabalho. Geroy, Wright e Anderson (1998), por exemplo, ressaltam que sua aplicação indevida pode não trazer os resultados potenciais desejados e pode também comprometer seus benefícios. Assim, surgem dúvidas de 'como', 'onde' e 'se' o Empowerment deve ser inserido no ambiente de trabalho.

Técnicas de Mapeamento de Processos, Gestão da Capacidade e Teoria das Restrições contribuem para responder a questão de 'onde' o Empowerment deve ser introduzido. Já questões de 'como' e 'se' o Empowerment deve ser inserido podem ser desdobradas no próprio âmbito do tópico Empowerment, através da verificação do nível de maturidade e responsabilidade dos funcionários e do levantamento do conteúdo do trabalho.

Observa-se, na prática, que estas técnicas de gestão são adotadas isoladamente. Assim, abre-se a oportunidade de se aplicarem conceitos já existentes sob uma perspectiva diferente, a do uso conjunto destas técnicas. 
De fato, mais de duzentos títulos (periódicos internacionais e nacionais, artigos de eventos científicos e livros) foram pesquisados pelos autores deste artigo e mais de cinquenta foram utilizados para a construção do referencial teórico para integração das técnicas. Nesta pesquisa bibliográfica, não se encontrou obra alguma que tratasse da utilização conjunta das quatro técnicas citadas. Em poucos trabalhos, se observou o uso conjunto de dois dos quatro assuntos e, raramente, três dos quatro.

Neste artigo, se descreve a integração de técnicas aplicadas a uma empresa de prestação de serviços (Banco) com resultados auspiciosos. Observou-se que a aplicação conjunta dos conceitos de Mapeamento de Processos, Gestão da Capacidade, Teoria das Restrições e de Empowerment foi útil para aprimorar os processos e reduzir custos de tramitação de informações e de pessoal.

0 artigo está assim estruturado: a seção 2 apresenta os aspectos metodológicos e a classificação da pesquisa; as seções 3, 4, 5 e 6 abordam os conceitos acerca de Mapeamento de Processos, Gestão da Capacidade, Teoria das Restrições e Empowerment, respectivamente; na seção 7, está a contextualização do problema abordado; a seção 8 mostra os resultados obtidos, e a última seção apresenta as principais conclusões.

\section{Metodologia e classificação da pesquisa}

0 método adotado na pesquisa teve duas etapas principais: pesquisa bibliográfica e estudo de caso. Após efetuar-se a pesquisa bibliográfica sobre Mapeamento de Processos, Gestão da Capacidade, Teoria das Restrições e Empowerment, foi identificada a possibilidade de integração dos mesmos. Na sequência, foi desenvolvido um estudo de caso em uma instituição financeira, envolvendo uma agência bancária, uma diretoria regional, uma diretoria estadual e diversos gerentes gerais e de negócios de várias agências pertencentes àquela mesma empresa.

0 estudo de caso abordou o mapeamento (em nível macro) das atividades principais de uma agência bancária, o mapeamento das atividades do departamento restritivo (gargalo), o levantamento do fluxo médio de pessoas atendidas em cada departamento, além da realização de entrevistas com gerentes gerais e de negócios.

0 mapeamento das atividades bancárias e 0 levantamento do fluxo médio de pessoas atendidas em cada departamento - que tiveram por finalidade proporcionar maior entendimento do processo produtivo de uma agência bancária - se deram a partir da observação direta do trabalho realizado na agência por nove dias, durante três meses consecutivos, ou seja, três dias de observação em cada mês. Foram selecionados, para análise, o primeiro, o quinto e o último dia útil de cada mês, uma vez que o fluxo de pessoas aumenta consideravelmente nesses dias.

Quanto às entrevistas, estas foram realizadas com cinco gerentes gerais de uma diretoria regional que possuía 14 agências associadas, em um total de 35,71\% dos gestores. Uma característica obrigatória dos gestores pesquisados foi terem estagiado na diretoria estadual do Banco. Nesta, durante uma semana, analisavam e deferiam autorizações - que se encontravam fora da alçada dos gerentes de negócios - enviadas pelas agências.

Entrevistas também foram realizadas com 12 gerentes de negócios de uma população de 56, ou seja, 21,43\% do total, sendo utilizado um questionário estruturado de perguntas abertas, com a finalidade de analisar o nível de autonomia dos funcionários, o volume de autorizações enviadas para as diretorias regional e estadual, a taxa de deferimento destas autorizações (percentual aprovado em relação ao número de autorizações submetidas), entre outras informações.

Diante do exposto, com base em Yin (2001) e Richardson (1999), este artigo se enquadra como pesquisa exploratória, visto que envolve a pesquisa bibliográfica enquanto busca ampliar e aprofundar conhecimentos. Caracteriza-se, também, como estudo de caso, pois busca correlacionar as informações da pesquisa bibliográfica com os resultados na prática.

\section{Mapeamento de Processos: sua definição e tipologia principal}

Antes de se definir o que é Mapeamento de Processo, torna-se primordial saber o que é um processo. Harrington (1997) entende processo como um grupo de tarefas, interligadas logicamente, que utilizam os recursos da organização para gerar os resultados definidos e apoiando os seus objetivos. Cheung e Bal (1998) definem Mapeamento de Processos como a técnica de se colocar em um diagrama o processo de um setor, departamento ou organização, para orientação em suas fases de avaliação, desenho e desenvolvimento. Mello e Salgado (2005) alegam que, para se gerenciar um processo é necessário visualizá-lo, sendo corroborados nesta premissa por Tseng, Quinhai e Su (1999), segundo os quais o mapeamento de processos deve ter uma linguagem gráfica que 
permita: expor os detalhes do processo de modo gradual e controlado; descrevê-lo com precisão; focar a atenção nas interfaces do mapa do processo, e fornecer uma análise de processos consistente com o vocabulário do projeto. Uma vez que os processos estejam no mapa de processos, pode-se partir para mudanças na forma como a organização os gerencia para atender aos seus objetivos estratégicos (VILLELA, 2000).

0 Mapeamento de Processos desempenha o papel essencial de desafiar os processos existentes, criando oportunidades de melhoria do desempenho organizacional ao identificar interfaces críticas, criando as bases para implantação de novas e modernas tecnologias de informação e de integração empresarial (DATZ; MELO; FERNANDES, 2004).

Quanto às técnicas de mapeamento, a literatura acerca do assunto apresenta inúmeros tipos, com diferentes enfoques. Assim, torna-se imprescindível "filtrar" a técnica adequada para cada situação. Conforme Leal, Pinho e Corrêa (2003), as principais técnicas de mapeamento de processos são as seguintes:

- Fluxograma: técnica para se registrar um processo de maneira compacta, usando símbolos padronizados, representando os diversos passos ou eventos que ocorrem durante a execução de uma tarefa específica ou durante uma série de ações (BARNES, 1982);

- Mapofluxograma: é a representação do fluxograma do processo na própria área em que a atividade se desenvolve; a sua grande vantagem é a possibilidade de visualização do processo atrelado ao layout (BARNES, 1982);

- Integrated Computer Aided Manufacturing Definition (IDEF): permite uma análise completa dos processos por meio de suas entradas, saídas, restrições e interações (CHEUNG; BAL, 1998);

- Diagrama sistemático da UnifiedModeling Language (UML): linguagem gráfica para visualização, especificação, construção e documentação de sistemas de software, podendo ser utilizada, também, para modelar sistemas que não sejam de software (WILCOX; GURAU, 2003). Trata-se de um fluxograma com ênfase à atividade que ocorre ao longo do tempo, proporcionando uma forma padrão para a preparação de planos de arquitetura de projetos de sistemas, incluindo aspectos conceituais, tais como processos de negócios e funções do sistema (WILCOX; GURAU, 2003);

- Service Blueprint: técnica desenvolvida para o mapeamento dos processos de serviços, diferenciando-se dos fluxogramas por considerar a interação com o cliente, representando todas as transações que constituem o processo de entrega do serviço e identificando as atividades de linha de frente e as atividades de retaguarda, separadas pela denominada linha de visibilidade (SANTOS, 2000);

- Mapa do serviço: técnica para o mapeamento dos serviços, derivada da anterior e envolvendo a gestão do serviço como um todo e não somente o processo de entrega do serviço. Trata-se de uma técnica gerencial para representar, cronologicamente, as tarefas e atividades realizadas pelo cliente, pelo pessoal de linha de frente e pelo pessoal de suporte no desempenho de um serviço (KINGMANBRUNDAGE, 1995). Diferentemente do Service Blueprint, que divide as atividades apenas em termos de linha de frente e de retaguarda (linha de visibilidade), no mapa do serviço, as atividades são divididas em linhas de interação, visibilidade, interação interna e implementação.

\section{Gestão da Capacidade}

Reid e Sanders (2005), ao realçarem a importância da gestão da capacidade, afirmam que se a empresa não administrar corretamente sua capacidade, ela poderá descobrir que não dispõe de condições suficientes para atender às demandas dos clientes ou que tem excesso de capacidade ociosa. 0 conceito de capacidade, adotado neste trabalho, corresponde ao máximo nível de atividade - que agrega valor, em determinado período de tempo - que o processo pode realizar sob condições normais de operação, ou, simplesmente, o número máximo de unidades que podem ser produzidas em um determinado tempo (SLACK; CHAMBERS; JOHNSTON, 2002).

Para muitas empresas, a medição da capacidade pode ser feita de forma direta; entretanto, não existe uma forma única de mensurá-la e diversos fatores tornam seu uso um tanto complexo, como: ausências de empregados; quebra de equipamentos; atrasos na entrega de materiais, e diferentes cadências de produção para diferentes produtos e serviços (GAITHER; FRAZIER, 2004). 0 Quadro 1 mostra exemplos de como a capacidade pode ser mensurada por diferentes organizações. Observe-se que cada empresa pode medir a capacidade de diferentes maneiras e que a capacidade pode ser medida considerando-se as entradas ou as saídas.

No segmento de serviços, identificaram-se quatro situações diferentes - relevantes para esta pesquisa - ao tentar conciliar a demanda do cliente com a capacidade existente da operação (DAVIS; AQUILANO; CHASE, 2001). Estas situações são: (a) demanda excede a capacidade máxima, afastando os clientes; (b) demanda excede a 
capacidade ótima, resultando em mau atendimento aos clientes; (c) demanda iguala a capacidade ótima, e (d) a demanda é menor que a capacidade ótima, resultando em capacidade ociosa (Figura 1).

Quanto aos fatores que afetam a capacidade de uma empresa, Davis, Aquilano e Chase (2001) os separam ainda em externos e internos. Dentre os fatores externos, incluem-se: (a) legislação governamental (horas de trabalho, segurança, poluição); (b) acordos com sindicatos, e (c) capacidades do fornecedor. Dentre os fatores internos, incluem-se: (a) projeto de produto e serviço; (b) pessoal e empregos (treinamento do trabalhador, motivação, aprendizado, satisfação no emprego e métodos); (c) layout de planta e fluxo de processo; (d) capacidades e manutenção de equipamento; (e) administração de materiais; (f) sistemas de controle de qualidade, e (g) capacidades de administração.

Heizer e Render (2001) acrescentam à lista de Davis, Aquilano e Chase (2001) o fator gargalo, pois a maioria dos processos envolve múltiplas operações com capacidades distintas e um gargalo é a operação com a menor capacidade efetiva no processo, limitando a produção final. Neste caso, a melhoria da capacidade de um processo ocorre somente quando a capacidade do gargalo é aumentada por meio de investimentos em equipamentos, horas-extras, melhoria do processo, entre outras ações.

Ritzman e Krajewski (2004) descrevem um procedimento geral que pode ajudar os gerentes a tomar boas decisões acerca de capacidade, como (i) estimar as necessidades futuras de capacidade; (ii) identificar as faltas, comparando necessidades com a capacidade disponível; (iii) desenvolver alternativas para lidar com as faltas identificadas, e (iv) avaliar as alternativas.

\section{Conceitos, princípios, gerenciamento e parâmetros da Teoria das Restrições}

Segundo Watson, Blackstone e Gardiner (2007), a Teoria das Restrições (Theory of Constraints - TOC) é uma filosofia de gestão que surgiu do desenvolvimento de um sistema de informação chamado OPT (Optimized Production Technology), que busca fornecer programas de produção baseados na capacidade finita dos elementos dos sistemas produtivos.

A TOC é um método de gerenciamento que se concentra naquilo que impede a otimização do processo produtivo, ou seja, as restrições (SOUZA, 2005). A propósito, vale salientar o aspecto conceitual controverso do termo "Otimização" na OPT, o que levou à sua substituição pela denominação de TOC. A conceituação aceita atualmente é que restrição ou gargalo é qualquer coisa que limita um melhor desempenho do sistema em direção à meta (MABIN; BALDERSTONE, 2003).

Vale acrescentar também que a TOC baseia-se em dez princípios (COX; SPENCER, 2002) que, de fato, representam um elenco de regras de bom senso. 0 mérito da TOC está em enfatizar a importância do gargalo de uma forma estruturada e abrangente, segundo o pressuposto da racionalização de não se investir naquilo (recursos, esforços) que não agrega valor, mas tão somente despesas. Afinal, tudo agrega custo, mas nem tudo agrega valor. Vale lembrar que a TOC não utiliza o termo agregação de valor, como o faz a Produção Enxuta (WOMACK; JONES; ROOS, 2004), mas objetiva focar esforços naqueles recursos que farão diferença positiva na produção do sistema como um todo.

Quanto ao seu gerenciamento, a TOC baseia-se em cinco passos, visando à melhoria contínua (GARDINER, S. C.; BLACKSTONE; GARDINER, L. R., 1994; RAHMAN, 1998):

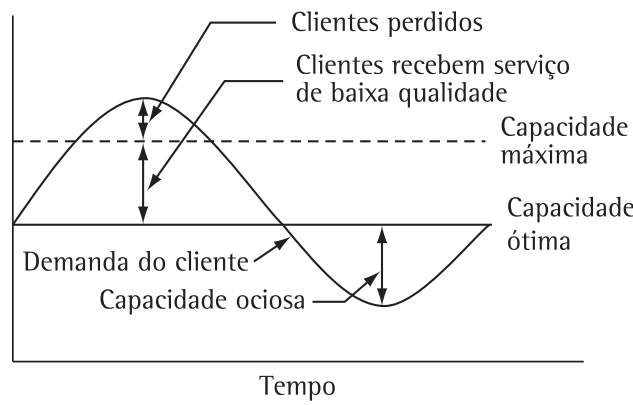

Figura 1. Tipos de capacidade de demanda em empresas de prestação de serviços. Fonte: Davis, Aquilano e Chase (2001).

Quadro 1. Diferentes indicadores para medição de capacidade.

\begin{tabular}{|c|c|c|}
\hline Tipo de empresa & Indicadores de capacidade de entrada & Indicadores de capacidade de saída \\
\hline Oficina de automóveis & Horas-homem & Carros por turno \\
\hline Hospital & Leitos disponíveis por mês & Número de pacientes por mês \\
\hline Pizzaria & Horas-homem por dia & Número de pizzas por dia \\
\hline Sorveteria & Horas operacionais por dia & Litros de sorvete por dia \\
\hline Loja varejista & Espaço no piso em metros quadrados & Receita diária \\
\hline
\end{tabular}

Fonte: Reid e Sanders (2005). 
- $1^{\circ}$ passo: Identificar a restrição do sistema;

- 20 passo: Decidir como explorar a restrição do sistema;

- $3^{\circ}$ passo: Subordinar tudo à decisão do segundo passo;

- $4^{\circ}$ passo: Elevar a restrição do sistema; e

- $5^{\circ}$ passo: Se uma restrição for quebrada, voltar ao primeiro passo, não deixando que a inércia seja uma restrição do sistema.

Quanto aos parâmetros da TOC, para Umble, M. e Umble, E. J. (2006), considera-se a sincronização do processo produtivo por meio da programação tambor-pulmão-corda, segundo a qual o desenvolvimento do Programa Mestre de Produção (PMP) relaciona-se com a programação da restrição. 0 objetivo do tambor é proporcionar que o gargalo opere 100\% do tempo, ditando o ritmo de produção; o pulmão deve proteger o gargalo da falta de material, e a corda deve garantir a taxa de entrega de material ao processo produtivo, sendo definida pelo ritmo de absorção do gargalo e pelo nível do pulmão.

A Figura 2 ajuda na compreensão da sincronização do processo produtivo pela TOC. 0 primeiro passo é a identificação do recurso gargalo. Uma vez identificado o gargalo, deverá ser definida uma quantidade de material que o protegerá em caso de eventualidades. A taxa de alimentação de matérias-primas na linha (corda) será ditada pelo ritmo do tambor (gargalo) e pela quantidade de material a ser acumulado (pulmão).

Todos os recursos que receberão materiais processados pelo gargalo farão parte da rede crítica de programação. A programação da produção dos recursos da rede crítica será feita a partir da data do gargalo até a data de entrega do produto definida pelo cliente (programação à frente ou forward scheduling). De maneira similar, os recursos que fazem parte da rede não crítica - não afetados pelo gargalo - têm sua produção estabelecida pela programação do gargalo (programação para trás ou backward scheduling).

Para garantir que haja sincronismo entre os materiais oriundos do gargalo e os oriundos dos demais recursos, a abordagem TOC recomenda estoques de materiais nas várias montagens subsequentes (pulmões de convergência), que ditarão também o ritmo de alimentação de suas matérias-primas (corda).

Em resumo, a TOC tem a filosofia de identificar e concentrar esforços no gargalo; desta forma, a taxa do gargalo será a taxa da sua linha e a melhoria desta linha será consequência da melhoria do gargalo.

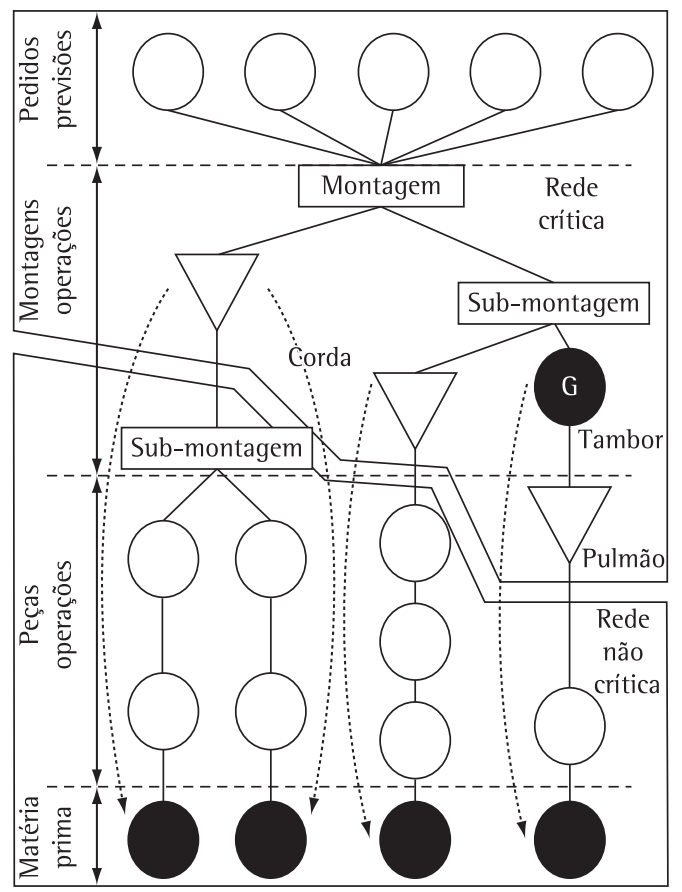

Figura 2. llustração da sincronização do processo produtivo por meio da TOC.

\section{Aspectos relacionados ao Empowerment}

Segundo Collins (1996), Honold (1997), Wilkinson (1998) e Greasley, Brtyman e King (2005), definir corretamente a palavra Empowerment demanda esforço, pois este termo pode ser usado para descrever tanto 0 aspecto individual das pessoas como o aspecto organizacional das empresas.

Marras (2001), Blanchard (2001) e Tracy (1994) conceituam o Empowerment como uma mudança organizacional, com objetivo de ampliar o sistema decisório até o menor nível possível na pirâmide organizacional, dando aos grupos de trabalho o poder e a autonomia de como realizar suas tarefas, reforçando-os com credibilidade e encorajando sua criatividade.

Wilkinson (1998) defende que o Empowerment se dá quando o trabalhador assume maior responsabilidade pelo planejamento e pelo controle do seu próprio trabalho, assumindo, também, a responsabilidade por decisões que, normalmente, estariam associadas às funções de gerência.

Neste trabalho, se entende por Empowerment o contexto em que a organização permite que 0 funcionário de linha de frente (aquele que atende o cliente) tenha a concessão de autonomia e responsabilidade para tomar decisões. Esta definição vai ao encontro àquela defendida por Val e Lloyd (2003), que associam o Empowerment à gestão 
participativa, dando ao empregado a autoridade para fazer mudanças na forma como o trabalho é desempenhado. Também vai ao encontro da definição de Greasley, Brtyman e King (2005), para os quais o Empowerment implica em mão-de-obra com maior grau de flexibilidade e mais liberdade em tomar decisões relativas ao trabalho.

$\mathrm{Na}$ pesquisa bibliográfica que embasou este artigo, constatou-se a ligação do Empowerment com redução de custos, melhoria na qualidade de vida dos funcionários, melhoria nos níveis de atendimento ao consumidor e, até mesmo, com a saúde mental e psíquica das pessoas (HONOLD, 1997; HUT e MOLLEMAN, 1998; WYER e MASON, 1999; WILKINSON, 1998; GEROY; WRIGHT; ANDERSON, 1998; HOLDWORTH e CARTWRIGHT, 2003).

Também se verificou a aplicabilidade do Empowerment em diversos handbooks de administração da produção, em que, das sete obras consultadas, 100\% possuem, ao menos, um tópico relativo ao assunto.

0 Quadro 2 resume alguns exemplos de resultados positivos a respeito da aplicação do Empowerment no contexto organizacional, mostrando algumas vertentes importantes relativas à sua aplicabilidade.
Sua relevância é tal que, segundo Correa, H. L. e Correa, C. A. (2005), Heizer e Render (2001) e Slack, Chambers e Johnston (2002), conceitos importantes como Just in Time, Autocontrole, Total Quality Management (TQM), Total Productive Maintenance (TPM), entre outros, são viabilizados por meio do Empowerment, pois os trabalhadores assumem responsabilidades por processos inteiros e não somente por tarefas, operações ou habilidades específicas. Corroborando com sua importância, Heizer e Render (2001), Reid e Sanders (2005), Davis, Aquilano e Chase (2001), Gaither e Frazier (2004), Ritzman e Krajewski (2004) afirmam que o Empowerment está diretamente relacionado à qualidade, uma vez que parte da filosofia da TQM é delegar poder aos empregados para procurarem problemas relativos à qualidade e corrigi-los.

Apesar de uma filosofia de gestão embasada no Empowerment trazer bons resultados para as organizações, julga-se que a aplicação desta prática em excesso pode comprometer seus benefícios (GEROY; WRIGHT; ANDERSON, 1998). Assim, Honold (1997) sugere que o Empowerment seja multidimensional, de forma que considere como os líderes conduzem, como os indivíduos reagem, como os semelhantes interagem e como os trabalhos

Quadro 2. Aplicação do Empowerment e seus resultados.

\begin{tabular}{|c|c|c|}
\hline Pesquisadores (Ano) & Tipo de pesquisa & $\begin{array}{l}\text { Resultados observados nas organizações } \\
\text { com Empowerment }\end{array}$ \\
\hline Menon (1995) & Entrevista com 311 empregados & $\begin{array}{l}\text { Aspectos positivos em relação à motivação, satisfação, } \\
\text { transmissão de conhecimento, inovação, conflito, stress e } \\
\text { compromisso. }\end{array}$ \\
\hline Ward (1995) & Entrevista com 75 funcionários & $\begin{array}{l}\text { Empregados possuem objetivos mais claros e consistentes; } \\
\text { a avaliação e o desenvolvimento das necessidades } \\
\text { profissionais dos empregados são realizados com maior } \\
\text { consistência; existe uma congruência entre os objetivos } \\
\text { corporativos, da gerência e dos funcionários operacionais. }\end{array}$ \\
\hline Spreitzer (1996) & $\begin{array}{l}\text { Entrevista com } 393 \text { gerentes das } \\
500 \text { maiores empresas, segundo } \\
\text { a revista Fortune }\end{array}$ & $\begin{array}{l}\text { Os gerentes possuem acesso mais fácil à informação e a } \\
\text { recursos; o clima de trabalho favorece a participação dos } \\
\text { empregados na condução da empresa. }\end{array}$ \\
\hline Swenson (1997) & Levantamento de dados & $\begin{array}{l}\text { Federal Express reduziu em } 13 \% \text { os erros de seus serviços } \\
\text { de entrega; Procter \& Gamble aumentou em } 40 \% \text { sua } \\
\text { produtividade; Dana Corporation reduziu seu lead time de } \\
\text { seis meses para seis semanas. }\end{array}$ \\
\hline Matthews, Diaz e Cole (2003) & Entrevista com 534 estudantes & $\begin{array}{l}\text { Funcionários mais competentes e interessados no sucesso } \\
\text { da organização em que trabalham. }\end{array}$ \\
\hline Rodrigues e Santos (2004) & Estudo de caso em duas empresas & $\begin{array}{l}\text { Aumento da velocidade de resposta para atender as novas } \\
\text { demandas dos clientes; maior capacidade de inovação; } \\
\text { funcionários mais capacitados para solucionar problemas. }\end{array}$ \\
\hline Oliveira e Rodriguez (2004) & $\begin{array}{l}\text { Estudo de caso em várias filiais } \\
\text { de uma empresa }\end{array}$ & $\begin{array}{l}\text { Melhoria na tomada de decisões e correção de problemas } \\
\text { de ordem operacional. }\end{array}$ \\
\hline Pearson e Moomaw (2005) & $\begin{array}{l}\text { Entrevista com } 300 \text { professores } \\
\text { do Estado da Flórida }\end{array}$ & $\begin{array}{l}\text { Redução de stress, aumento da satisfação e melhoria } \\
\text { do desempenho no ambiente de trabalho (escolas e } \\
\text { universidades). }\end{array}$ \\
\hline Tavolaro et al. (2007) & Estudo de caso em abatedouros & Prevenção de problemas de saúde em trabalhadores. \\
\hline
\end{tabular}


são estruturados. Por sua vez, Ford e Fottler (1996) propõem que o Empowerment leve em consideração aspectos inerentes ao contexto e ao conteúdo do trabalho, sendo segmentado em cinco tipos, cada um com seu propósito e espaço de aplicação (Figura 3).

Segundo Ford e Fottler (1996), os pontos A, B, C, D e E, indicados na Figura 3, representam:

- Ponto A: tipo de trabalho totalmente repetitivo, não requerendo aplicação do Empowerment, pois não há poder de tomada de decisão associado ao contexto ou ao conteúdo do trabalho;

- Ponto B: grande responsabilidade concedida ao funcionário para decidir acerca do conteúdo do trabalho, porém baixa responsabilidade para decidir em relação ao contexto. Devido a aspectos ligados à missão, há concessão de apenas "parte" do Empowerment;

- Ponto C: é a área mais peculiar de grupos autônomos de trabalho, pois seus componentes são envolvidos na identificação e na solução de problemas para o conteúdo e o contexto do trabalho. É denominado de Empowerment participativo, pois apresenta balanceamento entre a tomada de decisão acerca do conteúdo e do contexto do trabalho;

- Ponto D: há capacitação dos funcionários para decidirem acerca do contexto de trabalho, porém nenhuma autonomia para tomarem decisões relativas a seu conteúdo;

- Ponto E: área que requer total envolvimento dos funcionários no desenvolvimento da missão, no desdobramento das metas e nos objetivos organizacionais. Concede-se total autoridade para os empregados tomarem decisões acerca do conteúdo e do contexto do trabalho, sendo necessária grande confiança nas suas competências.

Quanto ao processo de implantação do Empowerment, Quinn e Spreitzer (1999) propõem que sejam observados aspectos referentes ao seu refinamento e à sua degradação, considerando os resultados obtidos a partir de cada uma das diversas fases representadas na Figura 4. Ou seja: se os resultados da inovação são positivos, esta filosofia de gestão é reforçada e difundida,

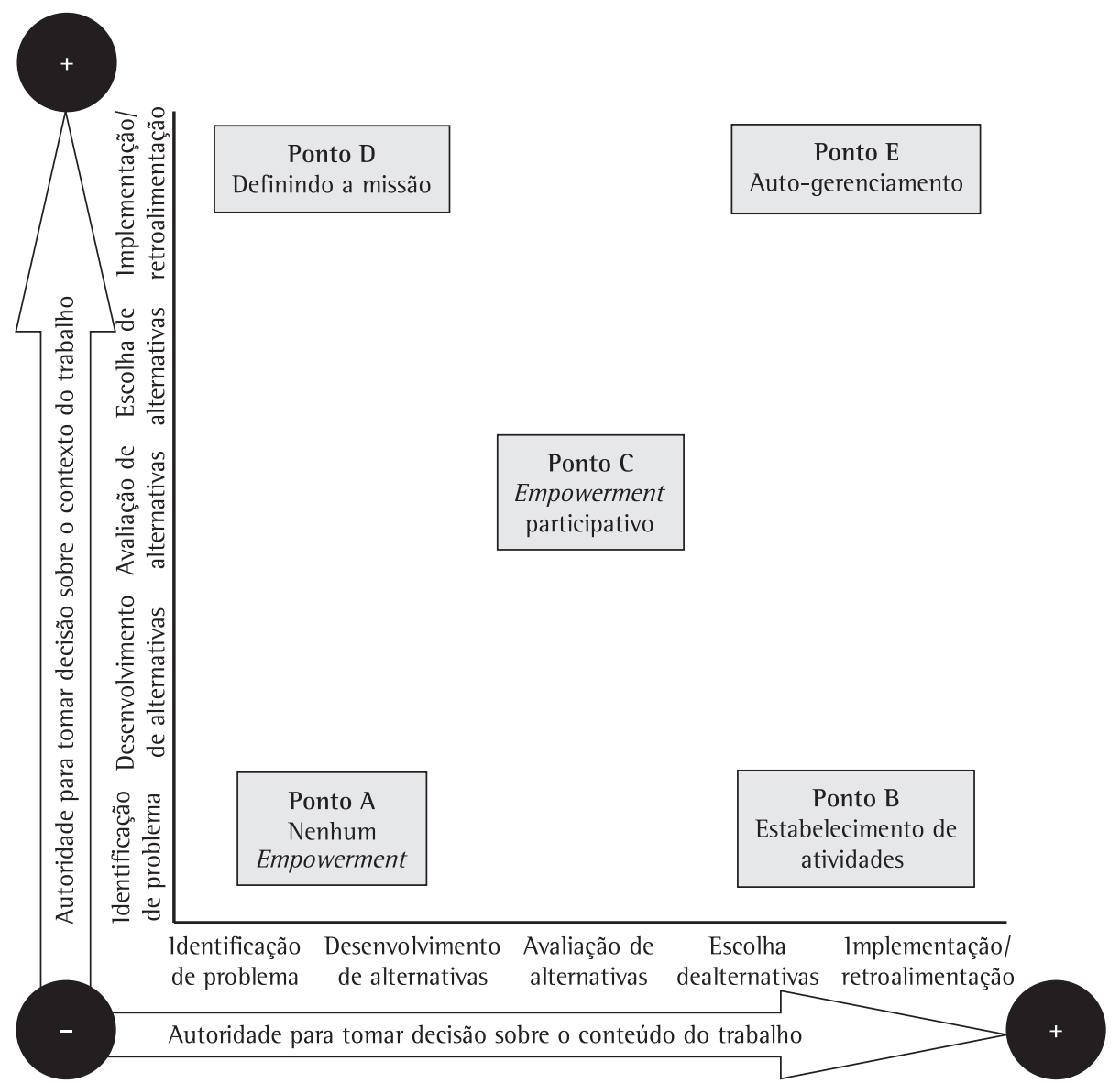

Figura 3. Tipologia do Empowerment. Fonte: Adaptado de Ford e Fottler (1996). 


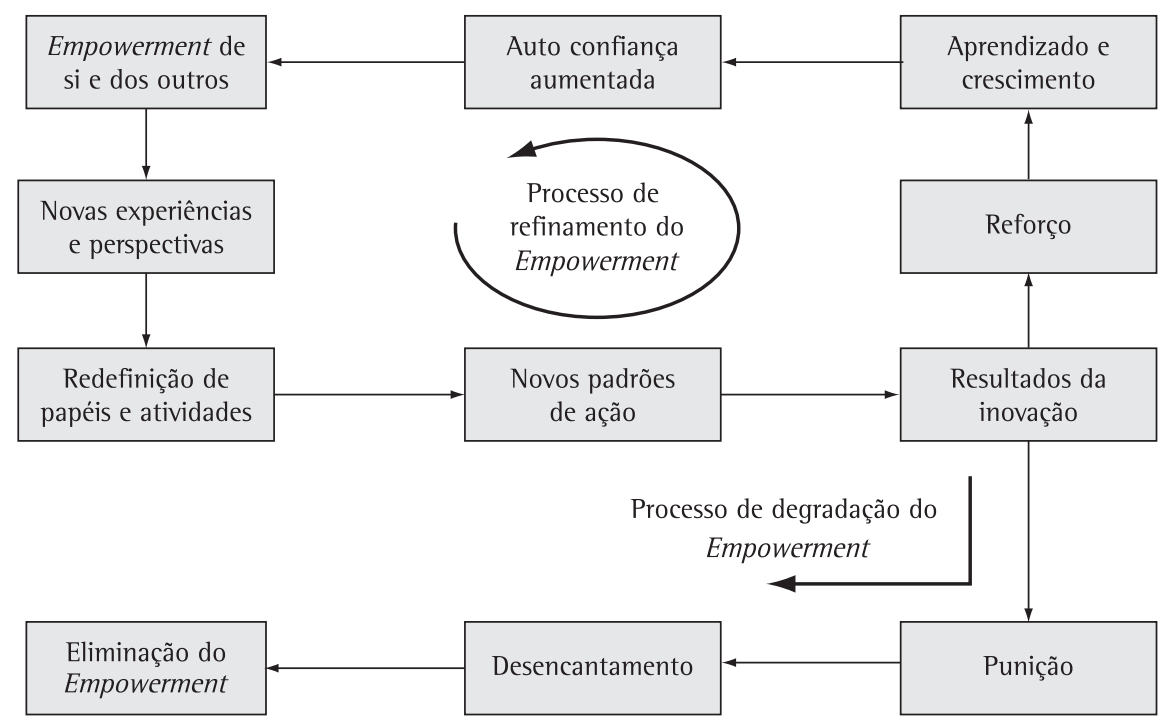

Figura 4. Ciclos do Empowerment. Fonte: Adaptado de Quinn e Spreitzer (1999).

tomando um rumo de crescimento e refinamento na organização; contudo, se os resultados são negativos, o Empowerment é eliminado.

Além destes, outros aspectos são levantados por Geroy, Wright e Anderson (1998), que observaram dois problemas frequentemente negligenciados nas empresas quando o assunto é Empowerment:

- autonomia e responsabilidade têm limites - os Autores sugerem a criação de autonomia por faixas, como uma solução favorável para o Empowerment. Note-se que, neste aspecto, forma-se um impasse, pois o problema é definir os limites de cada faixa; e

- Empowerment requer habilidades - a maturidade e a responsabilidade das pessoas - tanto as que concedem poder quanto aquelas que o recebem se tornam um componente crítico nesta filosofia.

Em resumo, este artigo parte do seguinte princípio: a autonomia deve ser concedida aos funcionários desde que eles demonstrem maturidade e responsabilidade para gerenciar suas atividades. Neste caso, a burocracia pode - e deve - ser reduzida, para que haja uma maior participação dos funcionários, maior satisfação dos clientes e maior volume de negócios.

\section{Contextualização do problema}

0 problema do Banco analisado caracterizava-se pela falta de autonomia dos gerentes de negócios na negociação de taxas e prazos para os financiamentos, provocando morosidade no atendimento, filas e perdas de negócios. Na maioria das operações, o gerente de negócios tinha de solicitar autorizações que eram repassadas, às vezes, para duas diretorias distintas.
0 sistema de alçadas e autorizações, então utilizado pelo Banco, ainda é empregado por inúmeras organizações do setor financeiro. Foi possível perceber que o problema não estava no sistema e sim no que era submetido ao sistema. Por exemplo:julgava-se que a submissão de autorizações para valores de empréstimos expressivos fosse válida; contudo, o que se constatou na pesquisa foi um volume expressivo de submissões de autorizações para empréstimos de valores inferiores a 5 mil reais. Estas autorizações normalmente eram submetidas para fazer frente a bancos concorrentes, com ofertas de taxas menores ou prazos maiores, ou ambos. A Figura 5 ilustra este sistema de concessão de empréstimos.

Na medida em que cerca de $60 \%$ das operações eram submetidas à apreciação de pelo menos uma diretoria, o cliente normalmente aguardava a liberação do financiamento em sua conta corrente por mais um dia e, em alguns casos, até dois dias, quando passava pela apreciação de duas diretorias (34\% dos casos). lsto causava morosidade e altos custos com o processo, pois mais pessoas e departamentos se envolviam na operação.

A falta de autonomia gerava excesso de serviço, demandando o dobro do tempo necessário para liberar uma operação de crédito de autonomia da agência, o que aumentava o ciclo do atendimento, gerava filas e, consequentemente, gargalos. A partir desta observação, efetuou-se um mapeamento do processo de atendimento da agência bancária, bem como foram coletadas informações acerca da capacidade média de atendimento de cada seção (Figura 6). 


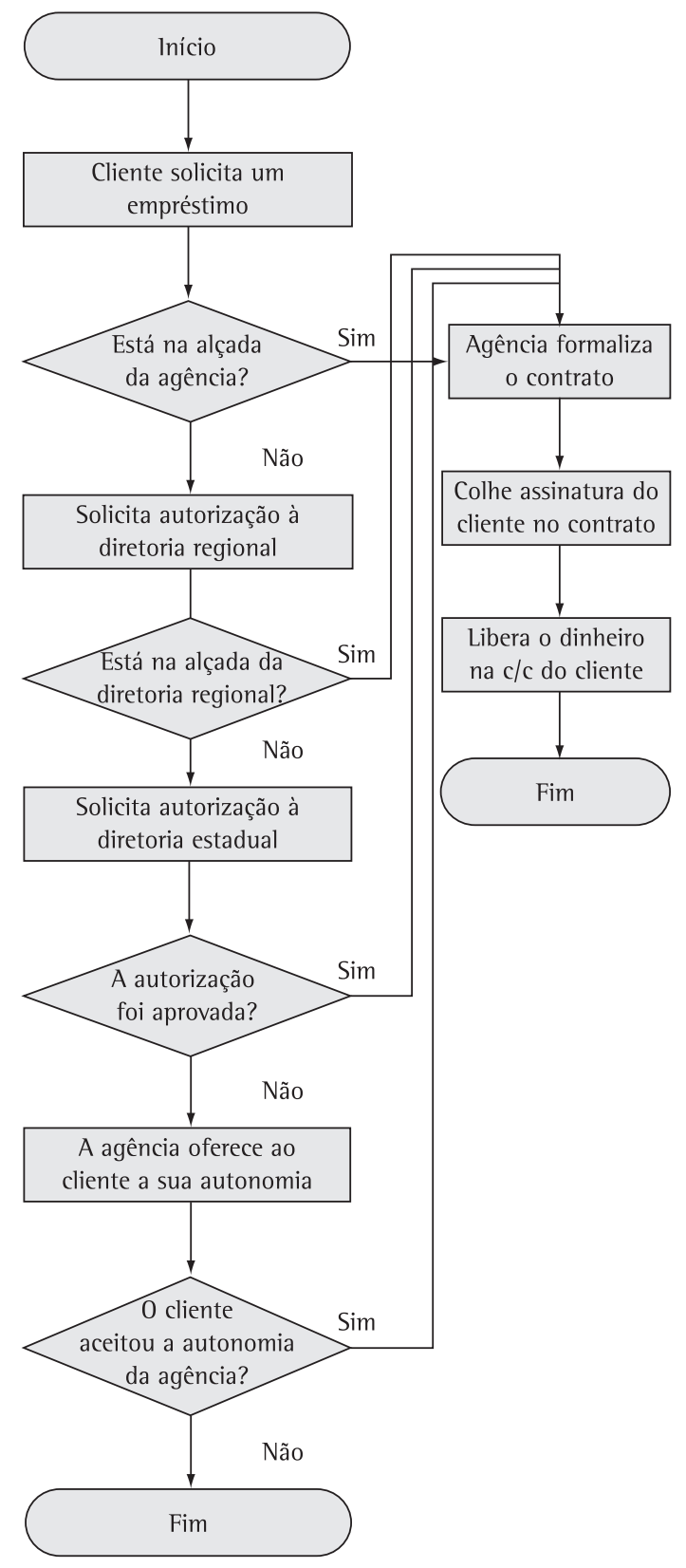

Figura 5. Mapeamento do processo de concessão de empréstimos.

\section{Resultados da pesquisa}

Após o entendimento do problema, procurou-se identificar, por meio de entrevistas junto aos funcionários da organização, a real necessidade da submissão de autorizações às diretorias regional e estadual. Ficou constatado que a maioria das solicitações formalizadas pelos gerentes de negócios era aprovada. Em entrevista com dois gerentes gerais que haviam estagiado na diretoria estadual da organização, os relatos foram:

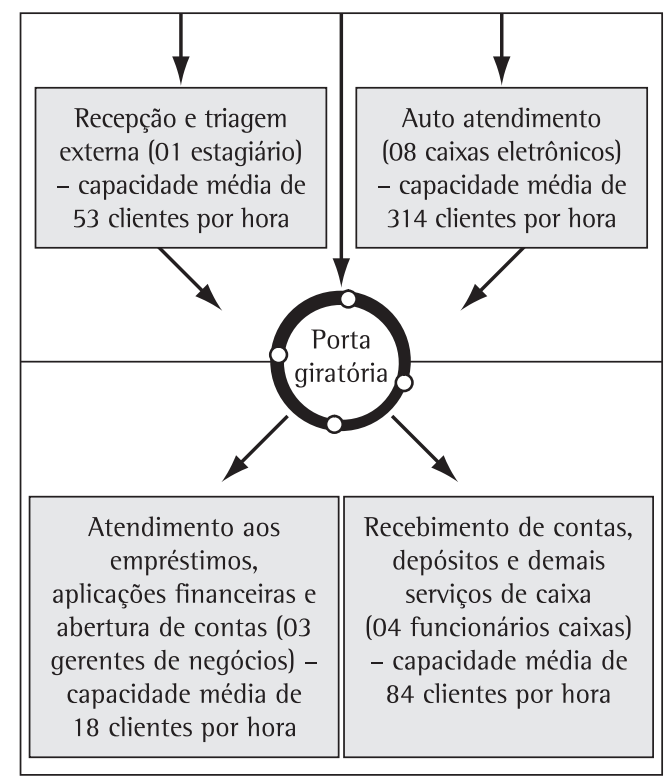

Figura 6. Mapofluxograma do atendimento da agência bancária.

[...] fiquei lá durante uma semana e por dia eu analisava mais de 500 autorizações. Dessas autorizações mais de $90 \%$ eram aprovadas e quando eu negava alguma era porque estava mal formulada e eu não conseguia entender o motivo da solicitação.

[...] era o dia inteiro aprovando autorizações. Olhava para o computador e ficava doido com o número de autorizações que tinha que analisar [...] engraçado que eram raras as vezes que eu negava alguma coisa.

Outros gerentes gerais foram entrevistados e as respostas foram, na maioria, muito parecidas; ou seja: a maior parte das submissões era aprovada. Quanto às entrevistas dos gerentes de negócios, que lidam diretamente com o cliente, as respostas foram do seguinte tipo:

[...] tudo o que eu envio para lá geralmente é aprovado. Por dia chego enviar, em média, mais de 10 pedidos de autorização e, raramente algum é negado. Ainda bem que tudo é aprovado [...] o problema é o tempo que perdemos com isso.

[...] a alçada da agência poderia ser aumentada, pois perco muito tempo escrevendo as autorizações. Esse tempo eu poderia estar na rua fazendo novos negócios [...], além disso, não peço nada que não possa ser aprovado.

Foi realizada, também, uma análise quantitativa, com os dados disponíveis, para checar se havia concordância dos resultados com as entrevistas efetuadas. Assim, analisou-se durante nove dias a quantidade exata de autorizações submetidas aos órgãos superiores (Tabela 1). 
Pela Tabela 1, observa-se um alto índice de aprovação das autorizações $(94,89 \%)$, confirmando o teor das entrevistas efetuadas e demonstrando um alto nível de maturidade dos funcionários em suas solicitações. Este dado vai ao encontro do princípio definido no referencial teórico sobre Empowerment: a autonomia deve ser concedida aos funcionários desde que eles demonstrem maturidade e responsabilidade para gerenciar suas atividades.

Desta forma, pôde-se propor que a decisão "sobre quais taxas e prazos praticar" deveria ficar a cargo dos gerentes de negócios, ou, no mínimo, que a autonomia da diretoria regional fosse repassada para a agência, permitindo que os negócios fluíssem mais rapidamente. Isto permitiria uma redução no tempo médio de atendimento para a concessão de um empréstimo - fora da autonomia

Tabela 1. Negócios submetidos à aprovação vs. negócios aprovados.

\begin{tabular}{|c|c|c|c|c|}
\hline \multirow[t]{2}{*}{$\begin{array}{l}\text { Dia } \\
\text { útil-mês }\end{array}$} & \multicolumn{2}{|c|}{$\begin{array}{l}\text { Número de negócios } \\
\text { na alçada da diretoria }\end{array}$} & \multirow{2}{*}{$\begin{array}{l}\text { Número de } \\
\text { negócios } \\
\text { aprovados }\end{array}$} & \multirow[t]{2}{*}{$\begin{array}{c}\text { \% de } \\
\text { aprovação }\end{array}$} \\
\hline & Regional & Estadual & & \\
\hline $1^{\circ}-A$ & 12 & 7 & 18 & 94,74 \\
\hline $5^{0}-A$ & 8 & 6 & 14 & 100,00 \\
\hline Último - A & 11 & 5 & 15 & 93,75 \\
\hline $1^{\circ}-B$ & 11 & 2 & 13 & 100,00 \\
\hline $5^{0}-B$ & 7 & 4 & 11 & 100,00 \\
\hline Último - B & 10 & 6 & 14 & 87,50 \\
\hline $1^{\circ}-C$ & 13 & 8 & 19 & 90,48 \\
\hline $5^{0}-C$ & 9 & 1 & 10 & 100,00 \\
\hline Último - C & 10 & 7 & 16 & 94,12 \\
\hline Total & 91 & 46 & 130 & 94,89 \\
\hline
\end{tabular}

da agência - de 35 para 19 minutos, conforme demonstra a Tabela 2.

Consequentemente, haveria um aumento da capacidade de atendimento deste departamento de 18 (Figura 6) para 23 clientes (Tabela 3), representando uma melhoria de 27,78\%. Esta seria a contribuição do Empowerment na Gestão de Capacidade e Teoria das Restrições, ou seja, se a autonomia fosse repassada para os gerentes de negócios, o gargalo seria amenizado e a capacidade produtiva seria aumentada.

Além do aumento na capacidade de atendimento do departamento gargalo em 27,78\%, o Empowerment também contribuiu para a satisfação do cliente (Quadro 3).

Finalizando esta seção, observa-se que o Empowerment pôde contribuir também para a redução de custos: estimou-se que 4,5 milhões de reais poderiam ser economizados em uma única diretoria estadual se a autonomia da diretoria regional (subordinada à diretoria estadual) fosse repassada aos gerentes de negócios - sendo que o nível de maturidade destes funcionários permite essa prática. Assim, o cargo de analista de crédito de cada diretoria regional poderia ser extinto, uma vez que esta função existe única e exclusivamente para deferir ou indeferir solicitações de autorizações submetidas a este órgão. Na medida em que são 14 diretorias regionais e como o custo salarial mensal de um analista de crédito - com os encargos - é próximo a 20 mil reais, a diretoria estadual poderia economizar, ao ano, o montante de 3 milhões e 640 mil reais ( 20 mil reais $\times 14$ diretorias regionais $\times 13$ meses de salário).

Tabela 2. Tipos de atividades, quantidades e tempos médios.

\begin{tabular}{lcc}
\hline \multicolumn{1}{c|}{ Atividade } & $\begin{array}{c}\text { Tempo médio } \\
\text { despendido } \\
\text { por atividade } \\
\text { (minutos) }\end{array}$ & $\begin{array}{c}\text { Quantidade média } \\
\text { de negócios por } \\
\text { dia, por gerente } \\
\text { de negócios }\end{array}$ \\
\hline $\begin{array}{l}\text { Empréstimo na autonomia da agência - envolve entrevista com o cliente e } \\
\text { formalização de contrato. }\end{array}$ & 19 & 3,63 \\
$\begin{array}{l}\text { Empréstimo fora da autonomia da agência - envolve entrevista com cliente, } \\
\text { solicitação de autorização e formalização de contrato. }\end{array}$ & 35 \\
$\begin{array}{l}\text { Aplicação financeira - envolve oferta ao cliente de diferentes tipos de aplicação, } \\
\text { explicar cada produto e formalizar a aplicação. Normalmente, o cliente já sabe } \\
\text { qual aplicação fará, o que minimiza o prazo médio de atendimento. }\end{array}$ & 5 \\
$\begin{array}{l}\text { Abertura de conta corrente - envolve entrevista com o cliente, coleta de } \\
\text { documentos e assinatura em formulário específico. A parte operacional } \\
\text { (consulta ao SERASA, SPC, preenchimento de documentos, referências e } \\
\text { inclusão da conta corrente no sistema) é efetuada por outro funcionário } \\
\text { designado para essa função. }\end{array}$ & 14 \\
$\begin{array}{l}\text { Outros - envolve tudo o que não é empréstimos, aplicações financeiras e } \\
\text { abertura de conta corrente (consulta de saldos, extratos e aplicações financeiras } \\
\text { para clientes, informações diversas, reclamações, entre outros). }\end{array}$ & 3,19 \\
\hline
\end{tabular}


Tabela 3. Tempos de realização de atividades 'com' e ‘sem' o Empowerment.

\begin{tabular}{lc}
\multicolumn{1}{c}{ Item } & Tempos \\
\hline $\begin{array}{l}\text { Tempo médio total despendido nas atividades diárias de um } \\
\text { gerente de negócios, sem Empowerment }\end{array}$ & 353,04 minutos \\
$\begin{array}{l}\text { Quantidade média total de negócios (clientes atendidos) diários } \\
\text { de um gerente de negócios, sem Empowerment }\end{array}$ & 35,23 negócios / clientes atendidos \\
Tempo médio de um atendimento de um gerente de negócios, & $(3,63+5,07+7,19+1,15+18,19)$ \\
sem Empowerment & 10,02 minutos por cliente \\
Tempo total aproximado a ser reduzido para um gerente de & $(353,04 / 35,23)$ \\
negócios com o Empowerment & 81,12 minutos \\
Novo tempo total aproximado a ser despendido nas atividades & {$[5,07 \times(35-19)]$} \\
diárias de um gerente de negócios, após o Empowerment & 271,92 minutos \\
& $(353,04-81,12)$ \\
Novo tempo médio de um atendimento, após o Empowerment & 7,72 minutos por cliente \\
Nova taxa horária de atendimento de um gerente de negócios, & $(271,92 / 35,23)$ \\
após o Empowerment & 7,77 clientes por hora \\
Nova taxa horária de atendimento do departamento gargalo, & $(60 / 7,72)$ \\
após o Empowerment & 23,31 clientes \\
\hline
\end{tabular}

Quadro 3. Aspectos de melhoria para o cliente.

\begin{tabular}{|l|c|}
\hline \multicolumn{1}{|c|}{ ltem } & Quantificações \\
\hline $\begin{array}{l}\text { Tempo médio de duração de um atendimento qualquer ao cliente } \\
\text { (exclusivamente efetuado por gerentes), sem Empowerment }\end{array}$ & 10,02 minutos \\
\hline $\begin{array}{l}\text { Tempo médio de duração de uma operação de empréstimos para um } \\
\text { cliente, sem Empowerment }\end{array}$ & 35 minutos \\
\hline $\begin{array}{l}\text { Tempo máximo (pior cenário) para liberação de uma operação de } \\
\text { empréstimo para um cliente, sem Empowerment }\end{array}$ & 48 horas a partir do momento da solicitação \\
de autorização à diretoria
\end{tabular}

Além disto, poderia haver economia no custo da informação. 0 Banco estimou que cada informação inserida em seu sistema de processamento de dados custava o equivalente a 0,82 centavos de reais (custo unitário por transação) e, como à diretoria estadual eram submetidas, aproximadamente, 1.137.117 autorizações por ano (média de 15,22 negócios por dia numa agência $\times 22$ dias úteis $\times 12$ meses $\times 283$ agências), estimou-se uma economia de 932 mil e 436 reais em custos com informação.

\section{Conclusões}

No estudo de caso realizado, constatou-se que a integração entre Mapeamento de Processos, Gestão de Capacidade, Teoria das Restrições e Empowerment contribuiu para a melhoria do processo produtivo, reduzindo o tempo médio de atendimento de cada cliente, proporcionando maior agilidade na concessão de empréstimos, reduzindo custos e amenizando as restrições provenientes do departamento gargalo. 
Por intermédio dos cinco passos da TOC, demonstrou-se que é possível, também, melhorar a produtividade de uma empresa de prestação de serviços. Enfatiza-se o 'também' nesta última frase, uma vez que, segundo Cia (1998), ao contrário da indústria, os processos dentro de um banco não são sucessivos e sim paralelos, acontecendo ao mesmo tempo. Na medida em que, geralmente, não existe uma ordem temporal entre estes processos, torna-se mais difícil a aplicação dos conceitos inerentes a Teoria das Restrições.

0 primeiro passo (identificação das restrições) foi o mapeamento da capacidade de cada departamento (Figura 6), por meio do qual se identificou o departamento de empréstimos como sendo o gargalo da agência bancária; no segundo passo (decidir como explorar as restrições do sistema), efetuou-se um mapeamento de processo de concessão de empréstimos (Figura 5), englobando entrevistas com os gerentes gerais e de negócios e levantamento de dados sobre autorizações de empréstimos submetidas, atividades realizadas pelos gerentes de negócios e seus respectivos tempos de execução (Tabelas 1 e 2), com vistas a explorar a restrição do sistema. 0 terceiro passo (subordinar os demais departamentos ao departamento gargalo) não se aplica à situação, uma vez que a produção na referida agência bancária era paralela e não sucessiva (quando diversas transações acontecem ao mesmo tempo). Assim, o uso do tambor, que dita o ritmo da produção, não se enquadrava neste estudo.

Por sua vez, elevar a restrição do sistema (passo 4) foi possível, em parte, pela aplicação da filosofia de gestão do Empowerment, sendo viável aumentar a capacidade produtiva do departamento gargalo em 27,78\%. Ressalte-se que a restrição não foi totalmente eliminada, porém obteve-se um aumento de capacidade que gerou melhorias no setor de empréstimos, de aplicações financeiras e de abertura de contas correntes.

0 processo de concessão de empréstimos anteriormente adotado, mapeado na Figura 5, gerava uma média de 15 submissões de autorizações por dia em somente uma única agência. Esta quantidade era relativamente pequena - e talvez por isto não tenha sido dada a real importância da aplicação de uma ação para melhorar o atual processo - quando comparada com a quantidade anual total de autorizações submetidas àquela diretoria estadual, ou seja, mais de um milhão de autorizações. Para esta quantidade de autorizações, eram necessárias mais de 300 mil horas anuais de trabalho, que poderiam ser utilizadas para outras atividades que agregassem valor para a organização.

Neste caso, recomendou-se que a faixa de autonomia da agência terminasse onde a faixa de autonomia da diretoria estadual se iniciava, extinguindo-se, então, a faixa de responsabilidades da diretoria regional. Esta sugestão foi tecnicamente viável, pois o nível de maturidade dos funcionários, requisito principal para a aplicação do Empowerment, foi devidamente comprovado para a atividade de concessão de empréstimos, uma vez que aproximadamente 95\% das autorizações solicitadas eram autorizadas (Tabela 1).

No tocante aos custos, uma das prioridades competitivas em gestão de operações, observou-se que a adoção da ação sugerida permitiria uma redução de 4,5 milhões de reais com salários e informações, simplesmente com a transferência de autonomia da diretoria regional para a agência.

Quanto à satisfação dos clientes, houve melhorias significativas relacionadas a tempo de atendimento, tempo de espera, tempo de aprovação de uma operação e quantidades de deslocamentos até a agência bancária (Quadro 3).

Finalizando, o presente estudo mostrou que a integração entre as técnicas abordadas é possível e viável. Para que os benefícios desta integração possam ser formalizados no meio acadêmico, novas pesquisas em empresas de manufatura, comércio e, também, em outras empresas do setor de serviços se fazem necessárias, visando uma possível generalização dos resultados obtidos.

\section{Referências}

BARNES, R. M. Estudo de movimentos e de tempos. 6 ed. São Paulo: Edgard Blücher Editora, 1982.

BLANCHARD, K. H. As três chaves do empowerment. São Paulo: Record, 2001.

CHEUNG, Y.; BAL, J. Process analysis techniques and tools for business improvements. Business Process Management Journal, v. 4, n. 4, p. 274-290, 1998.

CIA, J. N. S. Sistema de Gerenciamento de Liquidez sob a Ótica da Teoria das Restrições. Uma Adaptação da Metodologia Fleuriet. 1998. Tese (Doutorado em Administração de Empresas) - EAESP/FGV, São Paulo, SP.

COLLINS, D. Control and isolation in the management of Empowerment. Empowerment in Organizations, v. 4 n. 2, p. 29-39, 1996.

CORREA, H. L.; CORREA, C. A. Administração de Produção e Operações: Manufatura e Serviços. São Paulo: Atlas, 2005.

COX, J. F.; SPENCER, M. S. Manual da Teoria das Restrições. Porto Alegre: Bookman, 2002.

DATZ, D.; MELO, A. C. S.; FERNANDES, E. Mapeamento de processos como instrumento de apoio à implementação 
do custeio baseado em atividades nas organizações. In: ENCONTRO NACIONAL DE ENGENHARIA DE PRODUÇÃO, 2004, Florianópolis. Anais... CD-ROM.

DAVIS, M.; AQUILANO, N.; CHASE, R. Fundamentos da Administração da Produção. Porto Alegre: Bookman, 2001.

FORD, R. C.; FOTTLER, M. D. Empowerment: a matter of degree. IEEE Engineering Management Review, v. 24, n. 3, p. 19-24, Fall 1996.

GAITHER, N.; FRAZIER, G. Administração da Produção e Operações. São Paulo: Thomson Learning, 2004.

GARDINER, S. C.; BLACKSTONE, J. H.; GARDINER, L. R. The evolution of the Theory of Constraints. Industrial Management. v. 36, n. 3, p. 13-16, May/Jun 1994.

GEROY, G. D.; WRIGHT, P. C.; ANDERSON, J. Strategic Performance Empowerment Model. Empowerment in Organizations, v. 6, n. 2, p. 57-65, 1998.

GREASLEY, K.; BRYMAN, A.; KING, N. Employee perceptions of Empowerment. Employee Relations, v. 27, n. 4, p. 354-368, 2005.

HARRINGTON, J. Business process improvement workbook: documentation, analysis, design and management of business process improvement. New York: McGraw-Hill, 1997.

HEIZER, J.; RENDER, B. Administração de Operações. Rio de Janeiro: LTC, 2001.

HOLDWORTH, L.; CARTWRIGHT, S. Empowerment, Stress and Satisfaction: an exploratory study of a call centre. Leadership e Organization Development Journal, v. 24, n. 3, p. 131-140, 2003.

HONOLD, L. A review of the literature on employee Empowerment. Empowerment in Organizations, v. 5, n. 4, p. 202-212, 1997.

HUT, J.; MOLLEMAN, E. Empowerment and team development. Team Performance Management, v. 4, n. 2, p. 53-66, 1998.

KINGMAN-BRUNDAGE, J. Service mapping: back to basics. In: Understanding services management. Integrating marketing, organisational behaviour, operations and human resource management. John Wiley and Sons, 1995.

LEAL, F.; PINHO, A. F.; CORRÊA, K. E. S. Análise comparativa de técnicas de mapeamento de processo aplicadas a uma célula de manufatura. In: SIMPÓSIO DE ENGENHARIA DE PRODUÇÃO, 10, 2003, Bauru, SP. Anais...

MABIN, V. J.; BALDERSTONE, S. J. The Performance of the Theory of Constraints Methodology: analysis and discussion of successful TOC applications. International Journal of Operations and Production Management, v. 23, n. 6, p. 568-595, 2003.

MARRAS, J. P. Administração de recursos humanos: do operacional ao estratégico. São Paulo: Futura, 2001.

MATTHEWS, R. A.; DIAZ, W. M.; COLE, S. G. The organizational Empowerment scale. Personnel Review, v. 32, n. 3, p. 297-318, 2003.

MELLO, C. H. P.; SALGADO, E. G. Mapeamento dos processos em serviços: estudo de caso em duas pequenas empresas da área de saúde. In: ENCONTRO NACIONAL DE ENGENHARIA DE PRODUÇÃO, 25, 2005, Porto Alegre. Anais...
MENON, S. T. Employee Empowerment: Definition, Measurement and Construct Validation. Canada: McGill University, 1995.

OLIVEIRA, U. R.; RODRIGUEZ, M. V. Empowerment como ferramenta de gestão de pessoas para a redução dos custos e aumento da eficiência operacional: Um estudo de caso em uma instituição financeira. In: ENCONTRO NACIONAL EM ENGENHARIA DE PRODUÇÃO, 24, 2004, Florianópolis. Anais...

OLIVEIRA, U. R.; DELAMARO, M. C.; MARINS, F. A. S. A Percepção dos funcionários sobre o Empowerment como estratégia competitiva: Aplicação em manufatura e serviços. In: SIMPÓSIO DE GESTÃOO E ESTRATÉGIA EM NEGÓClOS, 4, 2006, Seropédica - RJ. Anais eletrônicos..

PEARSON, L. C.; MOOMAW, W. The relationship between teacher autonomy and stress, work satisfaction, Empowerment and professionalism. Educational research quarterly, v. 29, n. 1, p. 38-54, Sept. 2005.

OUINN, R. E.; SPREITZER, G. M. The road to empowerment: seven questions every leader should consider. IEEE Engineering Management Review, v. 27, n. 2, p. 21-28, Summer 1999.

RAHMAN, S. Theory of Constraints: a review of the philosophy and its applications. International Journal of Operations and Production Management, v. 18, n. 4, p. 336-355, 1998.

REID, D.; SANDERS, N. Gestão de Operações. Rio de Janeiro: LTC, 2005.

RICHARDSON, R. J. Pesquisa Social: Métodos e Técnicas. São Paulo: Atlas, 1999.

RITZMAN, L. P.; KRAJEWSKl, L. J. Administração da Produção e Operações. São Paulo: Prentice Hall, 2004.

RODRIGUES, C. H. R.; SANTOS, F. C. A. Empowerment: Estudo de casos em empresas manufatureiras. Revista Gestão e Produção, v. 11, n. 2, p. 263-274, 2004.

SANTOS, L. C. Projeto e análise de processos de serviços: avaliação de técnicas e aplicação em uma biblioteca. 2000. Dissertação (Mestrado em Engenharia de Produção) - Universidade Federal de Santa Catarina, Florianópolis.

SLACK, N.; CHAMBERS, S.; JOHNSTON, R. Administração da Produção. São Paulo: Atlas, 2002.

SOUZA, F. B. Do OPT à Teoria das Restrições: Avanços e Mitos. Revista Produção, v. 15, n. 2, p. 184-197, 2005.

SPREITZER, G. M. Social structural characteristics of psychological empowerment. Academy of Management Journal, v. 39, n. 2, p. 483-504, 1996.

SWENSON, D. Requisite conditions for team empowerment Empowerment in Organizations, v. 5, n. 1, p. 16-25, 1997.

TAVOLARO, P. et al. Empowerment como forma de prevenção de problemas de saúde em trabalhadores de abatedouros. Revista Saúde Pública, v. 41, p. 307-312, 2007.

TRACY, D. 10 Passos para o Empowerment. Rio de Janeiro: Campus, 1994.

TSENG, M. M.; QINHAl, M.; SU, C. J. Mapping Customers' Service Experience for Operations Improvement. Business Process Management Journal, v. 5, n. 1, p. 50-64, 1999.

UMBLE, M.; UMBLE, E. J. Utilizing buffer management to improve performance in a healthcare environment. European Journal of Operational Research, v. 174, n. 2, p. 1060-1075, 2006. 
VAL, M. P. D.; LLOYD, B. Measuring Empowerment. Leadership e Organization Development Journal, v. 24, n. 2, p. 102-108, 2003.

VILLELA, C. S. Mapeamento de Processos como Ferramenta de Reestruturação e Aprendizado Organizacional. 2000. Dissertação (Mestrado em Engenharia de Produção) Universidade Federal de Santa Catarina, Florianópolis.

WARD, P. J. A study of organizational variables affecting worker empowerment. Educational and Psychological Studies, 1995.

WATSON, K. J.; BLACKSTONE, J. H.; GARDINER, S. C. The evolution of a management philosophy: the theory of constraints. Journal of Operations Management, v. 25, n. 2, p. 387-402, 2007.
WILKINSON, A. Empowerment: theory and practice. Personnel Review, v. 27, n. 1, p. 40-56, 1998.

WYER, P.; MASON, J. Empowerment in small Businesses. Participation e Empowerment: An International Journal, v. 7, n. 7, p. 180-193, 1999.

WILCOX, P. A.; GURAU, C. Business modelling with UML: the implementation of CRM systems for online retailing. Journal of Retailing and Consumer Services, n. 10, p.181-191, 2003.

WOMACK, J. P.; JONES, D. T.; ROOS, D. A máquina que mudou o mundo. 10 ed. Rio de Janeiro: Elsevier, 2004.

YIN, R. K. Estudo de caso: Planejamento e métodos. Porto Alegre: Bookman, 2001.

\title{
Integrating operations management techniques and procedures: an application in a major Brazilian bank
}

\begin{abstract}
In today's conjuncture characterized by extreme global competition, cost elimination, customer satisfaction and productivity are rather essential for organizations to survive and compete. In accordance with this scenario, the present research proposes an integrated approach of many operations management philosophies and techniques, which are usually adopted in an isolated manner by many companies. The proposed approach integrates process mapping techniques, capacity management, Theory of Constraints and Empowerment and was applied to a credit concession process of a major Brazilian bank. Through employee interviews, primary data collection and direct observation it was possible to map processes, define capacities, identify bottlenecks, determine the personnel maturity level and, as a consequence, propose a solution by means of the Empowerment approach. As a result, a productivity increase of $27.78 \%$ and a cost reduction of nearly US $\$ 2.7$ million were obtained with the improvements in the credit concession process.
\end{abstract}

\section{Keywords}

Capacity Management. Process Mapping. Empowerment. Theory of Constraints. 